\section{INTERVENCIÓN DE BARRIO PARA LA TRANSFORMACIÓN: APLICACIÓN AL PROGRAMA QUIERO MI BARRIO, CHILE}

\author{
Antonio Fritis Estay ${ }^{1, *}$, Gabriela Diaz Valdivieso ${ }^{2}$, Iván Salaz Lizana ${ }^{3}$ y Karla Salinas Constanso ${ }^{3}$
}

\section{RESUMEN}

El año 2006 se implementa en el Ministerio de Vivienda y Urbanismo de Chile el Programa Quiero mi Barrio, con el desafío de abordar el déficit cualitativo de los barrios en las ciudades chilenas y de esta forma enfrentar la inequidad urbana. Tras trece años, el programa ha implementado 610 barrios y se ha convertido en una política pública regular. En diferentes desastres ocurridos entre el 2010 y 2015, el Programa Quiero mi Barrio trabajó una propuesta piloto que incorporaba la gestión de riesgo de desastres en 4 barrios. Junto a la Facultad de Arquitectura y Urbanismo de la Universidad de Chile, se desarrolló una metodología experimental que propone medir mediante un Índice de Gestión de Riesgos (IGR) los logros alcanzados en esta materia. Para este artículo se aplica el IGR en tres barrios intervenidos por el Programa Quiero mi Barrio en la ciudad de Valparaíso. Cada intervención responde a un desastre originado por un incendio distinto. El objetivo es mostrar cómo el IGR se refleja tras las intervenciones y de esta forma mide el impacto en la política pública que estructura el programa.

\section{PALABRAS CLAVE}

Transformación, Barrios, Política pública, Resiliencia

\section{NEIGHBORHOOD INTERVENTIONS FOR TRANSFORMATION: INTERVENING THROUGH THE QUIERO MI BARRIO PROGRAM IN CHILE}

\section{ABSTRACT}

In 2006, the Quiero Mi Barrio Program was established by the Chilean Ministry of Housing and Urban Planning to address the qualitative deficit of housing and well-equipped neighborhoods in Chilean cities, and therefore addressing urban inequality. After thirteen years, the program has addressed 610 neighborhoods and it has become a regular public policy. In different disasters between 2010 and 2015, the Quiero Mi Barrio Program worked on a pilot proposal that incorporated disaster risk management (DRM) in 4 neighborhoods. Alongside the Faculty of Architecture and Urbanism of the Universidad de Chile, an experimental methodology was developed to measure the achievements on DRM named Risk Management Index (IGR). For this article, the IGR is applied in three neighborhoods operated by the Quiero Mi Barrio Program in the city of Valparaíso. Each intervention responds to a disaster caused by a different fire event. The objective is to show how the IGR is reflected after specific neighborhood interventions and in this way assess the impact on the public policy that structures the program.

\section{KEYWORDS}

Transformation, Neighborhood, Public policy, Resilience

\begin{abstract}
1. Programa Quiero Mi Barrio, Ministerio de Vivienda y Urbanismo MINVU, Santiago, Chile.

2. Departamento de Geografía, Facultad de Arquitectura y Urbanismo, Universidad de Chile, Santiago, Chile.

3. Secretaría Regional Ministerial SEREMI Valparaíso, Programa Quiero Mi Barrio, Valparaíso, Chile.

*Autor de correspondencia: afritis@minvu.cl
\end{abstract}

\section{RECIBIDO}

16 de mayo de 2019

\section{ACEPTADO}

29 de mayo de 2019

\section{PUBLICADO}

1 de julio de 2019

\section{Formato cita}

Recomendada (APA): Fritis Estay, A. Diaz

Valdivieso, G. Salaz Lizana, I. \& Salinas Constanso, K. (2019). Intervención de Barrio para la

Transformación: Aplicación al Programa Quiero mi Barrio, Chile. Revista de Estudios Latinoamericanos sobre Reducción del Riesgo de Desastres REDER, 3(2), 84-96.

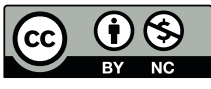

Todos los artículos publicados en REDER siguen una política de Acceso Abierto y se respaldan en una Licencia CreativeCommons Atribución-NoComercial 4.0 Internacional.

\section{Revista de Estudios}

Latinoamericanos sobre Reducción del Riesgo de Desastres (REDER)

Diseño: Lupe Bezzina Tipografía: Hospital 


\section{INTRODUCCIÓN}

La configuración geográfica de Chile hace que el territorio nacional esté expuesto a múltiples amenazas de origen natural, lo que complementado con las condiciones de vulnerabilidad que provoca el crecimiento urbano desregulado y el cambio climático, hacen que se configuren nuevos escenarios de riesgos que deben ser considerados dentro del ordenamiento territorial y su marco institucional a fin de evitar desastres en el futuro (Castro et al., 2008; UNISDR, 2015; ONEMI, 2016). Lo anterior se evidencia a través de los desastres ocurridos en Chile en la última década: erupciones volcánicas en el 2008, 2011 y 2015; terremotos los años 2010, 2014 y 2015; tsunami el año 2010, incendios urbanos y forestales los años 2014 y 2015; aluviones e inundaciones en el 2015, los cuales que han afectado a una parte importante de la población, generando pérdidas económicas, destrucción e interrupción de los servicios básicos y la infraestructura pública, alteración del medio ambiente e incluso pérdidas de vidas humanas; desastres que han planteado el desafío de atender el problema del riesgo en un contexto de desarrollo sostenible con un enfoque prospectivo de prevención y mitigación de los riesgos.

La preocupación por la reducción del riesgo de desastres (RRD) forma parte de la agenda internacional, desarrollando estrategias intergubernamentales para la acción coordinada entre los países. Así fue como en el año 2005 se firma el Marco de Acción de Hyogo, aprobado por 168 países, entre ellos Chile, el cual tuvo como objetivo delinear una serie de principios y prioridades para la reducción de pérdidas humanas, económicas y ambientales provocadas por desastres, dentro de un periodo de 10 años. En la misma línea, el año 2015 se firma el Marco de Acción de Sendai, en el cual los países adscritos se comprometen a intensificar el trabajo mediante el fortalecimiento de las capacidades tanto de las instituciones, como de la sociedad civil y el mundo privado, reforzando la gobernanza local, e incorporando de manera integral la gestión del riesgo de desastres (GRD).

Incorporar por tanto mecanismos para RRD dentro de los organismos y las políticas públicas es un primer paso para lograr una efectiva GRD a largo plazo. Para ello, es preciso comprender que el riesgo se construye socialmente y que está fuertemente vinculado con los modelos de desarrollo, por lo que su reducción se logra mediante un conjunto de acciones integradas que buscan reducir la vulnerabilidad y las condiciones inseguras, atendiendo a las presiones dinámicas que obedecen a condiciones de carácter político, social y económico, vinculadas con las formas o modelos de desarrollo en un nivel macro (Blaikie et al., 1996) y que explicarían el desencadenamiento de desastres en los territorios.

En este contexto, en el año 2012 Chile conforma la Plataforma Nacional para la Reducción del Riesgo de Desastre coordinada por la Oficina Nacional de Emergencia (ONEMI), órgano de carácter multisectorial e interdisciplinario, cuyo objetivo es incorporar la reducción del riesgo de desastres de manera transversal en las políticas públicas, la planificación y los programas de desarrollo. Para lograrlo, lo primero que hace la plataforma es la elaboración de la Política Nacional de Gestión del Riesgo de Desastres (PNGR) publicada el año 2014, la cual propone cinco ejes estratégicos de acción que se concretizan a través del Plan. Siguiendo esta línea de trabajo, la propuesta realizada en el Programa Quiero mi Barrio, del Ministerio de Vivienda y Urbanismo (MINVU), fue elaborada en conjunto con la estudiante en práctica Gabriela Díaz -Geógrafa de la Universidad de Chile- y está orientada a incorporar acciones estratégicas para la GRD, teniendo como marco de referencia la PNGR, el Plan Estratégico Nacional para la Gestión del Riesgo de Desastres (PENGRD) y el contexto internacional en el cual éstas se enmarcan. Por tanto, este trabajo constituye un aporte desde las políticas públicas, y la gestión territorial asociadas al programa de Recuperación de Barrios del MINVU, para avanzar en la RRD en Chile.

La Secretaría Ejecutiva del programa Recuperación de Barrios del MINVU está orientada al mejoramiento del entorno barrial y el fortalecimiento de la participación ciudadana, ya que se reconocen éstos como ejes fundamentales dentro de las políticas habitacionales y urbanas del Estado (MINVU, 2008). Así, esta unidad técnica implementa una estrategia de intervención mediante el programa de recuperación de barrios para contribuir al mejoramiento y revitalización de los espacios públicos colectivos, así como también a la consolidación del tejido social de los barrios.

Para ello, nace el Programa Quiero mi Barrio, que tiene como objetivo mejorar la calidad de vida de los habitantes del barrio a través de un proceso participativo que involucra al ministerio, municipio y a la propia comunidad para la recuperación de los espacios y los equipamientos públicos, 
y para el fortalecimiento del tejido social en barrios que presentan problemas de deterioro urbano, segregación y vulnerabilidad social (MINVU, 2008).

Para la implementación de estos objetivos, el programa cuenta con una metodología llamada Modelo Operativo, la cual establece las estrategias de intervención y ejecución que se dividen en tres fases que en total duran 42 meses; la primera de ellas corresponde al proceso de diagnóstico participativo del barrio, identificando problemáticas y oportunidades en base a una imagen objetivo construida en comunidad, tras lo cual se genera un plan maestro y se constituye el Consejo Vecinal de Desarrollo (CVD) que es la contraparte vecinal del plan maestro, finalizando el proceso con la consolidación de un contrato tripartito, que suscribe el representante de los vecinos, el alcalde y el represéntate del Ministerio de Vivienda y Urbanismo en la región. Este contrato contiene los proyectos de obras y proyectos sociales que el Programa Quiero mi Barrio financiara dentro del plan maestro. En la segunda fase se ejecutan dichos proyectos mediante la implementación del plan de gestión de obras (PGO) y el plan de gestión social (PGS), además de un plan de gestión multisectorial. En todo este proceso el programa instala una oficina al interior del barrio con un profesional del área urbana y otro del área social y que son los responsables de implantar el programa en el territorio. Finalmente, en la tercera fase se evalúan los resultados obtenidos tras la implementación del programa y se proyecta una agenda futura por parte de otras instancias de intervención multisectorial en el territorio, de forma de darle continuidad y reconocimiento al CVD y a la comunidad como organismos de gestión local, consolidando así el fortalecimiento del barrio como organización comunitaria de forma permanente en el tiempo.

Por otra parte, el programa se basa en tres ejes transversales que guían el plan de acción: identidad y patrimonio, medio ambiente y seguridad. Dentro del eje de seguridad, se diseñó una estrategia para la reducción del riesgo de desastres que comenzó con un proyecto piloto en barrios de Valparaíso (bajo amenaza de incendio), Constitución, Talcahuano y Valdivia, estos últimos bajo la amenaza de terremoto y tsunami. A través del piloto se buscó incorporar la componente de GRD, como una estrategia territorial a nivel local para la prevención, mitigación y recuperación de los barrios ante eventos peligrosos, ya sean éstos de origen natural o antrópico.

Para incorporar la GRD al Programa Quiero mi Barrio, este piloto propuso algunos contenidos en Modelo Operativo del programa que van desde el diagnóstico, con la definición de una línea base, que identifica temas de medio ambiente, identidad y seguridad que se identifican en el diseño de propuesta, ejecución de obras y plan de gestión social. De esta forma, se propone complementar el Modelo Operativo con las etapas de GRD, entendida como los "esfuerzos sistemáticos dirigidos al análisis y a la gestión de los factores causales de los desastres, lo que incluye la reducción del grado de exposición a las amenazas, la disminución de la vulnerabilidad de la población y la propiedad, una gestión sensata de los suelos y del medio ambiente y el mejoramiento de la preparación ante los eventos adversos" (ONEMI, 2014, p. 51).

Para este artículo se consideraron tres casos en la ciudad de Valparaíso que, tras haber sido azotados por incendios entre el 2013-2017, adquirieron importantes aprendizajes relacionados tanto a la intervención física de obras como a la intervención social, y que generaron transformaciones que apuntaban a obtener barrios más resilientes e impactar la política pública de mejoramiento de barrios del ministerio.

Los 3 casos seleccionados en Valparaíso y sus áreas de afectación de incendio por año son: Puertas Negras, Cerro La Cruz y Rodelillo (ver Figura 1).

\section{METODOLOGÍA}

El presente trabajo consistió en la aplicación del Índice de Gestión de Riesgo (IGR) a los tres casos del Programa Quiero mi Barrio en Valparaíso, señalados anteriormente. En primer lugar, se presenta la propuesta metodológica que incorpora el IGR al programa, para luego hablar de su aplicación a estos tres casos.

Los principales métodos utilizados corresponden a la revisión, sistematización y análisis de información secundaria y casos de estudio, así como el proceso de validación del modelo a través de mesas de trabajo con equipos técnicos nacionales y regionales del programa.

Dentro del eje de seguridad del Modelo Operativo del Programa Quiero mi Barrio, se diseñó una Estrategia para la Reducción del Riesgo de Desastres que comenzó con un proyecto piloto en 
cuatro barrios de Valparaíso, cuatro barrios de Constitución, uno en Talcahuano y un barrio en Valdivia. A través del piloto se buscó incorporar el componente de reducción del riesgo de desastre (RRD), como una estrategia territorial a nivel local para la prevención, mitigación y recuperación de los barrios ante eventos peligrosos, ya sean éstos de origen natural o antrópico.

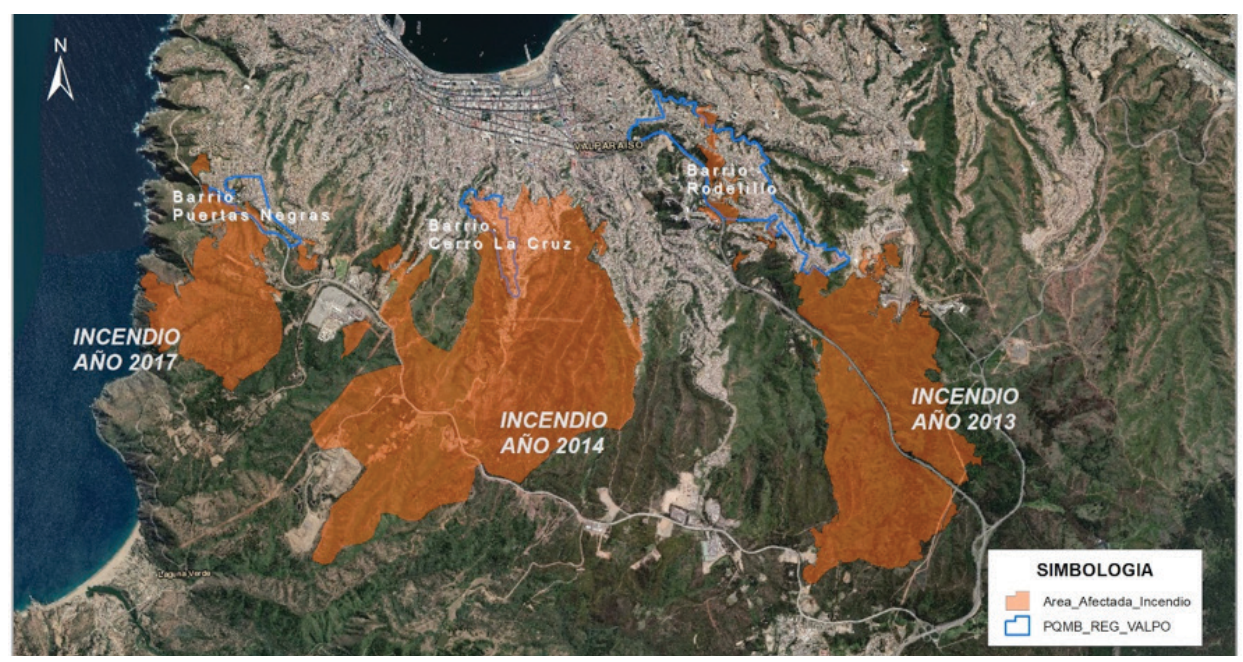

Figura 1. Tres casos del Programa Quiero mi Barrio en Valparaiso, afectadas por incendios entre 2013 y 2017 Fuente: Autores, 2019

Para incorporar la RRD al Programa Quiero mi Barrio, fue necesario delinear una propuesta metodológica que se adapte a su Modelo Operativo, la cual se ha trabajado con el siguiente equipo: estudiante en práctica Gabriela Díaz, profesor(es) guía(s) Carmen Paz Castro y Katherine Wyndham del Departamento de Geografía de la Universidad de Chile; y profesional a cargo de la practica Antonio Fritis (Programa Quiero mi Barrio, MINVU).

La RRD forma parte de la GRD, y se centra principalmente en la intervención de los factores subyacentes del riesgo, es decir, sobre aquellas condiciones socio-territoriales resultantes de los modelos actuales de desarrollo y de ocupación del territorio. El modelo de Presión y Liberación (PAR, por sus siglas en inglés: Pressure and Release) de Blaikie et al. (1996), como se ilustra en la Figura 2 , explica cómo los desastres son producto de la progresión de una serie de niveles de factores sociales que generan la vulnerabilidad. Dentro de los niveles jerárquicos de factores se encuentran, en primer lugar, las 'causas de fondo', que son los modelos de desarrollo y las macro estructuras políticas y económicas, los cuales inciden en el nivel intermedio de factores, llamadas 'presiones dinámicas', relacionadas con los contextos institucionales, procesos de ordenamiento territorial y de crecimiento urbano, y los procesos sociales. Por último, éstas presiones generan las 'condiciones de inseguridad' en un tercer nivel, que son los factores directos o las formas específicas en las cuales la vulnerabilidad de una población se expresa en el tiempo y espacio, y que explican que una amenaza natural resulte en un desastre (Blaikie et al., 1996).

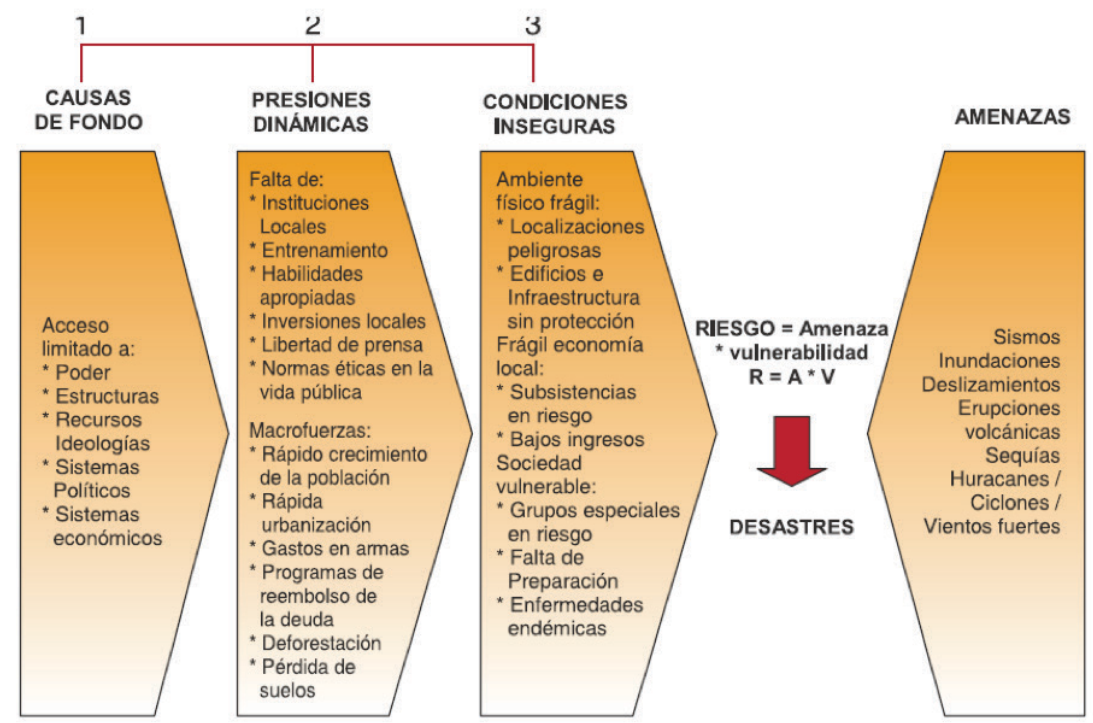

Figura 2. Modelo PAR de Blaikie et al. (1996)

Fuente: Blaikie et al., (1996) en Yamin et al. (2013) 
De esta forma, el modelo PAR ilustra las dimensiones del riesgo de desastres sobre las cuales el Programa Quiero mi Barrio tiene la potencialidad de intervenir. El programa debe centrarse en la intervención de las presiones dinámicas y las condiciones de inseguridad, desarrollando acciones estratégicas concretas aplicables a escala barrial que permitan modificar los escenarios de riesgos, disminuyendo así la vulnerabilidad y aportando entonces en la reducción del riesgo de desastres.

La metodología de gestión de riesgo de desastres para el Modelo Operativo se basó en el análisis del modelo y la revisión bibliográfica - de instrumentos normativos, políticas nacionales y mundiales sobre gestión del riesgo de desastres, documentos técnicos, académicos y científicos. Se sistematizaron estrategias viables para la RRD a nivel de barrio, a fin de incorporarla en el Programa Quiero mi Barrio. En este contexto, la utilización del IGR de IDEA (2005) permite identificar y seleccionar etapas y acciones para desarrollarlas dentro del programa, dando lugar a así a la propuesta de aplicación del IGR a nivel de barrio.

El IGR es un indicador compuesto cuya aplicación permite identificar y analizar el "estado de la organización, la capacidad, el desarrollo y la acción institucional para reducir la vulnerabilidad y el riesgo, y además el avance en la capacidad para responder en caso de crisis y recuperarse con eficiencia" (Carreño et al., 2004; Carreño et al., 2007b, en Yamin et al., 2013, p.855). El IGR contiene 4 indicadores: Identificación del riesgo (IR); Reducción del riesgo (RR); Manejo de desastres (MD); y Gobernabilidad y protección financiera (PF). Cada cual contiene 6 sub-indicadores de medición.

Como se trata de un instrumento que permite evaluar el estado de la GRD a nivel nacional, lo que se propone en este trabajo es una adaptación para que ciertos sub-indicadores del IGR, utilizables a escala de barrio, sean desarrollados aplicadamente en vez de sólo ser evaluados en su estado. De acuerdo a lo anterior, la propuesta desarrollada a continuación es una adaptación del IGR para ser aplicado a través de la metodología del Modelo Operativo del programa que trabaje con la componente de reducción del riesgo de desastres. Para ello, se han definido acciones a seguir por cada fase y etapa del Modelo Operativo existente (ver Figura 3).

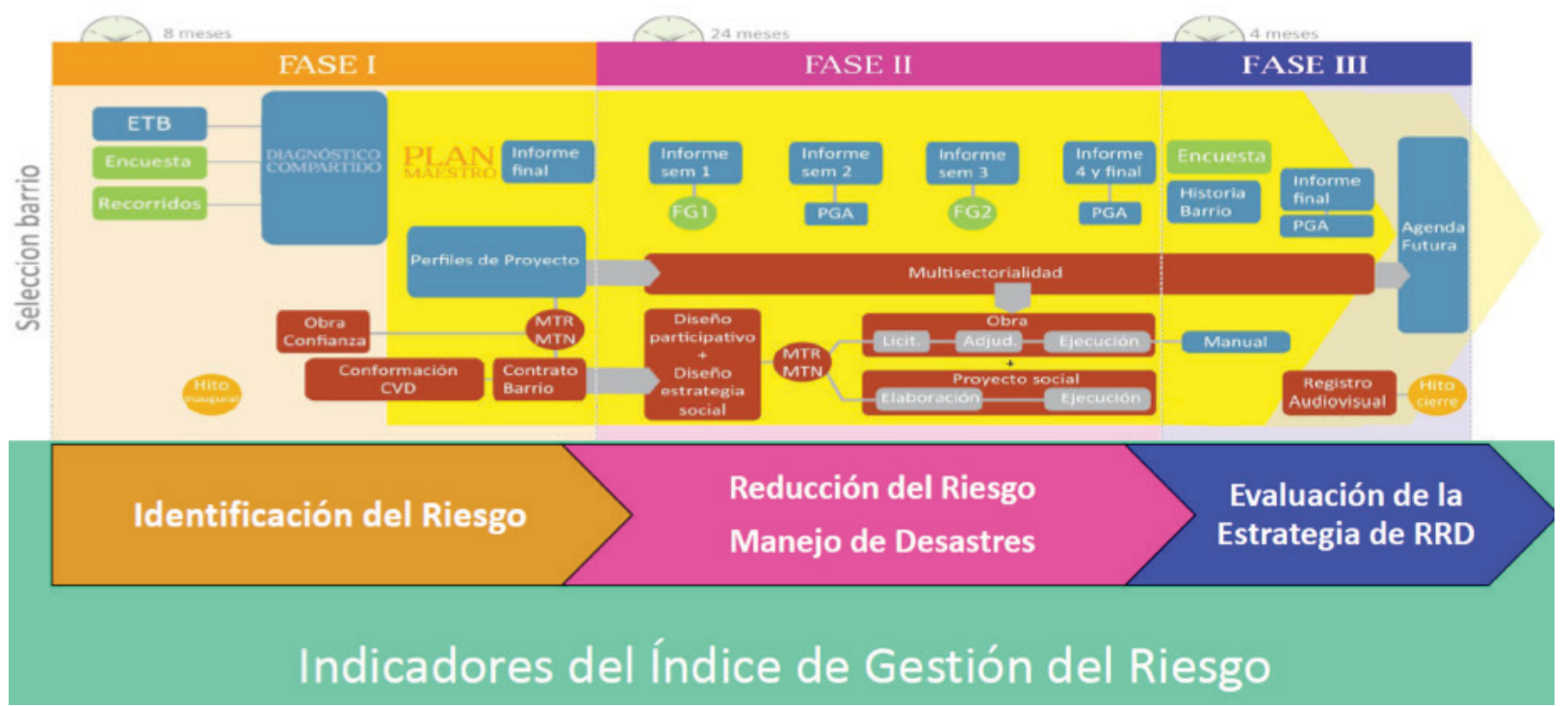

Figura 3. Modelo Operativo del Programa Quiero mi Barrio y aplicación del IGR en sus tres fases Fuente. Autores, 2019.

Al mismo tiempo, se proponen acciones específicas de RRD para cada una de las etapas señaladas -que tienen como marco de referencia los sub-indicadores del IGR-, las cuales consisten en herramientas, actividades, talleres y procedimientos para aplicar en cada etapa del Modelo Operativo. En la Tabla 1 se describe cada actividad propuesta para implementar en el Modelo Operativo del programa, según la etapa de RRD a la que corresponde.

Durante el proceso, se evalúa los logros y avances en RRD obtenidos a través de la ejecución del programa, incorporándolo como un capítulo dentro del informe final del barrio. Esto permite conocer en qué etapas de la propuesta y fases se lograron los mayores avances y cuáles de ellas fueron deficientes y requieren de mayores esfuerzos. Para esto se recomienda seguir las siguientes indicaciones 


\begin{tabular}{|c|c|c|c|c|}
\hline Fase & $\begin{array}{l}\text { Etapa Modelo } \\
\text { Operativo }\end{array}$ & Etapa RRD & Actividad & Descripción \\
\hline \multirow{7}{*}{$\begin{array}{l}F \\
A \\
S \\
E \\
\text { I }\end{array}$} & $\begin{array}{l}\text { Estudio Técnico de } \\
\text { Base }\end{array}$ & \multirow{7}{*}{$\begin{array}{l}\text { Identificación } \\
\text { del Riesgo (IR) }\end{array}$} & $\begin{array}{l}\text { Revisión de Instrumentos } \\
\text { de Planificación Territorial y } \\
\text { estudios de riesgo }\end{array}$ & $\begin{array}{l}\text { Realizar un levantamiento de los estudios de riesgo de los IPT (PRC, PROT, PRI, } \\
\text { etc.) y otros estudios que pudiesen existir para conocer las amenazas y } \\
\text { vulnerabilidades que la institucionalidad ha identificado y qué medidas se han } \\
\text { tomado para su reducción. }\end{array}$ \\
\hline & $\begin{array}{l}\text { Encuesta de } \\
\text { caracterización, } \\
\text { percepción y } \\
\text { satisfacción }\end{array}$ & & $\begin{array}{l}\text { Percepción y } \\
\text { Comportamiento del Riesgo } \\
\text { y Memoria Histórica de } \\
\text { Desastres }\end{array}$ & $\begin{array}{l}\text { Incluir preguntas sobre identificación de las amenazas, conocimiento, } \\
\text { comportamiento y estrategias del riesgo, y de memoria histórica en la encuesta, } \\
\text { a fin de incluir en el diagnóstico la manera en cómo percibe la población el riesgo } \\
\text { y cómo se comportarían frente a eventos de desastre y su valoración sobre } \\
\text { eventos pasados. Esta información permitirá analizar un posible cambio de } \\
\text { percepción/comportamiento al finalizar el programa, comparando con la } \\
\text { encuesta final. }\end{array}$ \\
\hline & \multirow[b]{2}{*}{ Recorridos Barriales } & & $\begin{array}{l}\text { Taller de Introducción a la } \\
\text { RRD }\end{array}$ & $\begin{array}{l}\text { Impartir talleres que permitan un entendimiento de lo que es el riesgo, su } \\
\text { manejo y sus conceptos fundamentales para luego ser aplicados en el recorrido. }\end{array}$ \\
\hline & & & Mapa de Riesgo & $\begin{array}{l}\text { Durante el recorrido se especializarán los lugares/vecinos que se encuentran } \\
\text { expuestos a amenazas y se identificará lavulnerabilidad tanto física como social } \\
\text { del barrio. El mapa consiste en la superposición de las amenazas con las } \\
\text { vulnerabilidades, y estará compuesto por un Mapa de Riesgo Técnico, elaborado } \\
\text { por el equipo técnico y una Cartografía Participativa, trabajada por la } \\
\text { comunidad. }\end{array}$ \\
\hline & Conformación CVD & & Conformación COE Barrial & $\begin{array}{l}\text { Paralelo a la conformación del CVD, conformar un Comité de Operaciones de } \\
\text { Emergencias Barrial (COE Barrial), el cual tendrá la función de gestionar y } \\
\text { desarrollar la coordinación con la comunidad, el municipio y otros actores en los } \\
\text { procesos de RRD, a través de un enfoque preventivo. EI COE Barrial tiene un } \\
\text { funcionamiento permanente en el tiempo más allá de la duración del programa, } \\
\text { encargándose de desarrollar los proyectos definidos por la agenda futura, en } \\
\text { coordinación con el municipio y organismos de protección civil. }\end{array}$ \\
\hline & $\begin{array}{l}\text { Diagnóstico } \\
\text { Compartido }\end{array}$ & & Capítulo sobre RRD & $\begin{array}{l}\text { Incluir un capitulo que dé cuenta del proceso llevado a cabo en la primera fase } \\
\text { de programa y de los resultados del diagnóstico, considerando la encuesta, el } \\
\text { taller, la revisión de IPT y el mapa de riesgo resultante. }\end{array}$ \\
\hline & Plan Maestro & & $\begin{array}{l}\text { Perfiles de Proyectos de } \\
\text { RRD }\end{array}$ & $\begin{array}{l}\text { Incluir un capitulo que describa las acciones propuestas para realizar en la fase } \\
\text { II en el contexto de la RRD, tanto desde el PGO, como del PGS y el plan de vivienda. }\end{array}$ \\
\hline \multirow{3}{*}{$\begin{array}{l}\text { F } \\
\text { A } \\
\text { S }\end{array}$} & \multirow[t]{2}{*}{$\begin{array}{l}\text { Plan de Gestión de } \\
\text { Obras }\end{array}$} & \multirow{3}{*}{$\begin{array}{l}\text { Reducción } \\
\text { del } \\
\text { Riesgo } \\
\text { (RR) }\end{array}$} & $\begin{array}{l}\text { Obras de Mitigación y } \\
\text { Mejoramiento de la } \\
\text { Seguridad en Espacios } \\
\text { públicos }\end{array}$ & $\begin{array}{l}\text { Tomar las medidas para que toda obra que se realice propenda a la seguridad y } \\
\text { la RRD, a través del mejoramiento de los espacios e infraestructura pública, y } \\
\text { diseñando obras de mitigación cuando sea necesario. }\end{array}$ \\
\hline & & & $\begin{array}{l}\text { Zonas de Seguridad y Vías } \\
\text { de Evacuación }\end{array}$ & $\begin{array}{l}\text { Incorporar el diseño e implementación de zonas de seguridad y vías de } \\
\text { evacuación con sus respectivas señaléticas cuando sea necesario. Para esto, se } \\
\text { recomienda considerar el entorno próximo para contribuir a la conformación de } \\
\text { un territorio seguro e integrado. }\end{array}$ \\
\hline & $\begin{array}{l}\text { Plan de Gestión de } \\
\text { Viviendas }\end{array}$ & & $\begin{array}{l}\text { Talleres de Seguridad al } \\
\text { interior de la vivienda }\end{array}$ & $\begin{array}{l}\text { Implementar técnicas de protección y control de fenómenos peligrosos al } \\
\text { interior de las viviendas. }\end{array}$ \\
\hline \multirow[t]{2}{*}{ II } & \multirow[t]{2}{*}{ Plan de Gestión Social } & \multirow{2}{*}{$\begin{array}{l}\text { Manejo de } \\
\text { Desastres } \\
\quad(\mathrm{MD})\end{array}$} & $\begin{array}{l}\text { Talleres por Tipo de } \\
\quad \text { Amenaza }\end{array}$ & $\begin{array}{l}\text { Desarrollarán talleres por los diferentes tipos de eventos identificados en el } \\
\text { territorio, entregando capacidades a la comunidad para disminuir sus } \\
\text { vulnerabilidades y aumentar su resiliencia. Esta etapa se debe sustentar en los } \\
\text { resultados de memoria histórica recopilados a través de la encuesta y del } \\
\text { proceso de diagnóstico de las fase I. }\end{array}$ \\
\hline & & & $\begin{array}{l}\text { Coordinación Multisectorial } \\
\text { para la preparación, } \\
\text { respuesta y recuperación }\end{array}$ & $\begin{array}{l}\text { Coordinar el trabajo multisectorial, fomentando la participación ciudadana, } \\
\text { mediante la asignación de roles a la comunidad, además de involucrar a } \\
\text { organismos del Estado con competencias en RRD y planificación urbana, y a los } \\
\text { agentes privados, fortaleciendo lazos y capacidades para la reducción del riesgo. }\end{array}$ \\
\hline \multirow{3}{*}{$\begin{array}{l}\text { F } \\
\text { A } \\
\text { S } \\
\text { E }\end{array}$} & $\begin{array}{l}\text { Encuesta de } \\
\text { caracterización, } \\
\text { percepción y } \\
\text { satisfacción } \\
\end{array}$ & \multirow{4}{*}{$\begin{array}{l}\text { Evaluación } \\
\text { de la } \\
\text { Estrategia de } \\
\text { RRD } \\
\text { (EE) }\end{array}$} & $\begin{array}{l}\text { Encuesta de Verificación de } \\
\text { Resultados }\end{array}$ & $\begin{array}{l}\text { Aplicar nuevamente la encuesta para identificar los cambios en la percepción y } \\
\text { comportamiento del riesgo, esperando un cambio positivo en cuanto a la } \\
\text { identificación de las amenazas, el conocimiento, comportamiento y estrategias } \\
\text { frente al riesgo y contribuir en la memoria histórica. }\end{array}$ \\
\hline & Historia de Barrio & & $\begin{array}{l}\text { Capítulo de Memoria } \\
\text { Histórica }\end{array}$ & $\begin{array}{l}\text { Incluir un capitulo que describa el proceso de RRD realizado en el libro "Historia } \\
\text { de Barrio", enfatizando Memoria Histórica sobre eventos pasados y sus } \\
\text { lecciones aprendidas. }\end{array}$ \\
\hline & Informe Final & & Capítulo de RRD & $\begin{array}{l}\text { Elaborar un capitulo en el informe final que contenga la descripción del proceso } \\
\text { de RRD en el barrio. }\end{array}$ \\
\hline III & Agenda Futura & & $\begin{array}{l}\text { Compromiso Municipal de } \\
\text { continuidad de la RRD }\end{array}$ & $\begin{array}{l}\text { Al finalizar el programa, comprometer la continuidad de los trabajos } \\
\text { desarrollados durante el programa, de manera de continuar con la RRD en el } \\
\text { barrio y la comuna. }\end{array}$ \\
\hline
\end{tabular}

Tabla 1. Sistematización de la propuesta de RRD en el Modelo Operativo

Fuente: Autores, 2019, basados en IDEA (2005) y en talleres de trabajo con equipo técnico del MINVU y Universidad de Chile.

Primero, completar la Tabla de Evaluación de Logros de las actividades de RRD (ver Tabla 2), marcando la actividad que sí fue realizada. De esta manera se contabiliza cuántas actividades de las propuestas fueron logradas. De acuerdo a la cantidad de actividades logradas se define el nivel de desempeño de la Estrategia de RRD por cada etapa.

Luego, según el nivel de desempeño obtenido en la aplicación de la tabla de logros (Tabla 2), se verifica el estado de la Estrategia de RRD en el barrio según las diferentes categorías: "Deficiente", "Aceptable" y "Óptimo" (ver Tabla 3). En esta etapa, por un lado, se describe el estado de dichas categorías por cada una de las etapas de la propuesta, y por otro, se entregan recomendaciones para la continuidad de la Estrategia de RRD en el barrio. 


\begin{tabular}{|c|c|c|c|c|}
\hline \multicolumn{3}{|c|}{ Actividad de RRD } & $\begin{array}{l}\text { Marque } \\
\operatorname{con} X\end{array}$ & Nivel de Desempeño \\
\hline \multicolumn{5}{|c|}{ FASEI } \\
\hline \multirow{10}{*}{$\begin{array}{l}\text { Identificación del } \\
\text { Riesgo } \\
\text { (IR) }\end{array}$} & \multicolumn{2}{|c|}{ 1. Revisión de Instrumentos de Planificación Territorial y estudios de riesgo. } & & \multirow{10}{*}{$\begin{array}{l}\text { Deficiente: Se realizaron entre } 0 \text { y } 3 \\
\text { actividades de RRD. } \\
\text { Aceptable: Se realizaron entre } 4 \text { y } 6 \\
\text { actividades de RRD. } \\
\text { Óptimo: Se realizaron entre } 7 \text { y } 9 \\
\text { actividades de RRD. }\end{array}$} \\
\hline & \multicolumn{2}{|c|}{$\begin{array}{l}\text { 2. Aplicación de encuesta de caracterización, percepción y satisfacción y } \\
\text { Memoria Histórica de Desastres. }\end{array}$} & & \\
\hline & \multirow{4}{*}{$\begin{array}{l}\text { Recorridos } \\
\text { Barriales }\end{array}$} & 3. Taller de Introducción a la RRD. & & \\
\hline & & 4. Recorrido barrial. & & \\
\hline & & 5. Cartografía Participativa de Riesgo de Desastres. & & \\
\hline & & 6. Mapa Técnico de Riesgo de Desastres. & & \\
\hline & \multicolumn{2}{|c|}{ 7. Conformación COE Barrial. } & & \\
\hline & \multicolumn{2}{|c|}{ 8. Incorporación de capítulo sobre RRD en Diagnóstico Compartido. } & & \\
\hline & \multicolumn{2}{|c|}{ 9. Desarrollo de Perfiles de Proyectos de RRD en el Plan Maestro. } & & \\
\hline & \multicolumn{2}{|c|}{ NÚMERO TOTAL DE ACTIVIDADES REALIZADAS } & & \\
\hline \multicolumn{5}{|c|}{ FASE II } \\
\hline \multirow{4}{*}{$\begin{array}{l}\text { Reducción del Riesgo } \\
\text { (RR) }\end{array}$} & \multirow{2}{*}{$\begin{array}{l}\text { Plan de Gestión } \\
\text { de Obras }\end{array}$} & $\begin{array}{l}\text { 1. Desarrollo de Obras de Mitigación y Mejoramiento de la } \\
\text { Seguridad en Espacios públicos. }\end{array}$ & & \multirow{4}{*}{$\begin{array}{c}\text { Deficiente: Se realizaron entre } 0 \text { y } 1 \\
\text { actividad de RRD. } \\
\text { Aceptable: Se realizaron } 2 \text { actividades de } \\
\text { RRD. } \\
\text { Óptimo: Se realizaron las } 3 \text { actividades de } \\
\text { RRD. }\end{array}$} \\
\hline & & $\begin{array}{l}\text { 2. Implementación de Zonas de Seguridad y Vías de } \\
\text { Evacuación. }\end{array}$ & & \\
\hline & $\begin{array}{l}\text { Plan de Gestión } \\
\text { de Viviendas }\end{array}$ & $\begin{array}{l}\text { 3. Desarrollo de Talleres de Seguridad al interior de la } \\
\text { vivienda. }\end{array}$ & & \\
\hline & \multicolumn{2}{|c|}{ NÚMERO TOTAL DE ACTIVIDADES REALIZADAS } & & \\
\hline \multirow{3}{*}{$\begin{array}{l}\text { Manejo del Desastre } \\
\text { (MD) }\end{array}$} & \multirow{2}{*}{$\begin{array}{l}\text { Plan de Gestión } \\
\text { Social }\end{array}$} & 1. Desarrollo de Talleres por Tipo de Amenaza. & & \multirow{3}{*}{$\begin{array}{c}\text { Deficiente: No se realizaron actividades de } \\
\text { RRD. } \\
\text { Aceptable: Se realizó } 1 \text { actividad de RRD. } \\
\text { Óptimo: Se realizaron } 2 \text { actividades de } \\
\text { RRD. }\end{array}$} \\
\hline & & $\begin{array}{l}\text { 2. Coordinación Multisectorial para la preparación, } \\
\text { respuestay recuperación. }\end{array}$ & & \\
\hline & \multicolumn{2}{|r|}{ NÚMERO TOTAL DE ACTIVIDADES REALIZADAS } & & \\
\hline \multicolumn{5}{|c|}{ FASE III } \\
\hline \multirow{5}{*}{$\begin{array}{l}\text { Evaluación de la } \\
\text { Estrategia } \\
\text { (EE) }\end{array}$} & \multicolumn{2}{|c|}{ 1. Aplicación de Encuesta de Verificación de Resultados. } & & \multirow{5}{*}{$\begin{array}{c}\text { Deficiente: Se realizaron entre } 0 \text { y } 1 \\
\text { actividades de RRD. } \\
\text { Aceptable: Se realizaron entre } 2 \text { y } 3 \\
\text { actividades de RRD. } \\
\text { Óptimo: Se realizaron las } 4 \text { actividades de } \\
\text { RRD. }\end{array}$} \\
\hline & \multicolumn{2}{|c|}{ 2. Incorporación de Capítulo de Memoria Histórica en "Historia de Barrio". } & & \\
\hline & \multicolumn{2}{|c|}{ 3. Incorporación de Capítulo de RRD en Informe Final. } & & \\
\hline & \multicolumn{2}{|c|}{$\begin{array}{l}\text { 4. Existencia de un Compromiso Municipal de continuidad de la RRD en Agenda } \\
\text { Futura. }\end{array}$} & & \\
\hline & \multicolumn{2}{|c|}{ NÚMERO TOTAL DE ACTIVIDADES REALIZADAS } & & \\
\hline
\end{tabular}

Tabla 2. Evaluación logros IGR

Fuente: Autores, 2019, basados en IDEA (2005) y en talleres de trabajo con equipo técnico del MINVU y Universidad de Chile.

\begin{tabular}{|c|c|c|c|}
\hline $\begin{array}{l}\text { Etapa de } \\
\text { RRD }\end{array}$ & $\begin{array}{l}\text { Nivel de } \\
\text { Desempeño }\end{array}$ & Descripción de los logros & Recomendaciones \\
\hline \multirow{3}{*}{$\begin{array}{l}\text { Identificación } \\
\text { del Riesgo } \\
\text { (IR) }\end{array}$} & Deficiente & $\begin{array}{l}\text { La población no tiene la información y conocimientos } \\
\text { suficientes para identificar y evaluar el riesgo de desastres } \\
\text { en el barrio. }\end{array}$ & $\begin{array}{l}\text { Se recomienda incentivar estrategias que permitan identificar } \\
\text { y evaluar el riesgo, asegurando la elaboración y difusión de un } \\
\text { mapa de riesgo actualizado permanentemente, el cual } \\
\text { considere las amenazas, vulnerabilidades y capacidades del } \\
\text { barrio. Para ello se recomienda fomentar el funcionamiento } \\
\text { permanente del COE barrial. }\end{array}$ \\
\hline & Aceptable & $\begin{array}{l}\text { Las actividades para identificar y evaluar el riesgo de } \\
\text { desastres entregan un conocimiento parcial de las } \\
\text { amenazas, vulnerabilidades y capacidades dentro del barrio. }\end{array}$ & $\begin{array}{l}\text { Se identifica un buen avance en la RRD, pero se debe mejorar } \\
\text { las estrategias de identificación y evaluación de las amenazas, } \\
\text { vulnerabilidades o capacidades. }\end{array}$ \\
\hline & Óptimo & $\begin{array}{l}\text { Las estrategias de identificación y evaluación del riesgo de } \\
\text { desastres en el barrio son efectivas y se ha logrado un } \\
\text { conocimiento generalizado en la población, las amenazas, } \\
\text { vulnerabilidades y capacidades. }\end{array}$ & $\begin{array}{l}\text { Se identifica un buen avance en la RRD, pero se } \\
\text { recomienda mejorar las estrategias de identificación y } \\
\text { evaluación de las amenazas, vulnerabilidades, y capacidades. }\end{array}$ \\
\hline \multirow{3}{*}{$\begin{array}{l}\text { Reducción } \\
\text { del Riesgo } \\
\text { (RR) }\end{array}$} & Deficiente & $\begin{array}{l}\text { El barrio aún no cuenta con las zonas de seguridad, } \\
\text { señaléticas vías de evacuación y/u obras de mitigación } \\
\text { necesarios. }\end{array}$ & $\begin{array}{l}\text { Se recomienda elaborar planes municipales, concursos o } \\
\text { subsidios o trabajo multisectorial en la agenda futura que } \\
\text { permitan implementarlos. }\end{array}$ \\
\hline & Aceptable & $\begin{array}{l}\text { El barrio no cuenta con todas las obras de reducción del } \\
\text { riesgo }\end{array}$ & $\begin{array}{l}\text { Se recomienda considerar a mediano-corto plazo completar } \\
\text { este tipo de obras. }\end{array}$ \\
\hline & Óptimo & $\begin{array}{l}\text { El barrio cuenta con obras de mitigación, seguridad y } \\
\text { señalética apropiada para la evacuación y conocimiento de } \\
\text { las zonas seguras. }\end{array}$ & $\begin{array}{l}\text { Las zonas de seguridad, señaléticas, vías de evacuación y/u } \\
\text { obras de mitigación del barrio deben contar con mantenimiento } \\
\text { continuo. }\end{array}$ \\
\hline \multirow{3}{*}{$\begin{array}{l}\text { Manejo de } \\
\text { Desastres } \\
\text { (MD) }\end{array}$} & Deficiente & $\begin{array}{l}\text { Existe una importante falta de coordinación para la } \\
\text { reducción del riesgoy preparación frente a emergencias. }\end{array}$ & $\begin{array}{l}\text { Se recomienda desarrollar estrategias con el COE, el municipio } \\
\text { y otros organismos encargados del sistema de protección civil } \\
\text { para organizar talleres y designar roles entre los participantes. }\end{array}$ \\
\hline & Aceptable & $\begin{array}{l}\text { Existe una incipiente organización a nivel del barrio -entre } \\
\text { vecinos y organizaciones de protección civil y el municipio- } \\
\text { para la coordinación en reducción del riesgo y preparación a } \\
\text { emergencias. Sin embargo, falta fortalecer las capacidades } \\
\text { comunitarias para una eficiente respuesta a los desastres. }\end{array}$ & $\begin{array}{l}\text { Se recomienda seguir organizando a la comunidad del barrio y } \\
\text { realizando talleres de amenazas, en conjunto con el municipio y } \\
\text { otros organismos para lograr una mayor organización de las } \\
\text { estrategias de RRD y atención a emergencias. }\end{array}$ \\
\hline & Óptimo & $\begin{array}{l}\text { Se ha logrado coordinar a los vecinos, el municipio y las } \\
\text { organizaciones de protección civil para elaborar un plan de } \\
\text { reducción del riesgo y de preparación con roles asignados en } \\
\text { casos de emergencia. }\end{array}$ & $\begin{array}{l}\text { Se recomienda realizar ejercicios de preparación con toda la } \\
\text { comunidad y generar planes a largo plazo sobre las estrategias } \\
\text { de RRD. }\end{array}$ \\
\hline \multirow{3}{*}{$\begin{array}{l}\text { Evaluación } \\
\quad \text { del } \\
\text { Programa } \\
\quad(E P)\end{array}$} & Deficiente & $\begin{array}{l}\text { No se ha aplicado la evaluación del programa o no se han } \\
\text { realizado los informes sobre la Estrategia de RRD del } \\
\text { programa. }\end{array}$ & $\begin{array}{l}\text { Se recomienda desarrollar una planificación multisectorial con } \\
\text { el municipio y el COE barrial para seguir trabajando las } \\
\text { estrategias de reducción del riesgo en la agenda futura. }\end{array}$ \\
\hline & Aceptable & $\begin{array}{l}\text { La evaluación y difusión de la Estrategia de RRD del } \\
\text { programa se ha realizado, pero necesita ser fortalecida. }\end{array}$ & $\begin{array}{l}\text { Se recomienda fortalecer las herramientas de comunicación y } \\
\text { difusión del proceso de reducción del riesgo del programa y } \\
\text { seguir con el trabajo multisectorial en un corto y largo plazo. }\end{array}$ \\
\hline & Óptimo & $\begin{array}{l}\text { Los informes sobre las estrategias de reducción del riesgo } \\
\text { del programa han sido efectivos y se ha logrado contribuir a } \\
\text { la RRD en el barrio. }\end{array}$ & $\begin{array}{l}\text { Se recomienda mantener en constante actualización y difusión } \\
\text { todo el proceso de RRD para la permanente efectividad de la } \\
\text { estrategia. }\end{array}$ \\
\hline
\end{tabular}

Tabla 3. Recomendaciones según nivel de desempeño del programa

Fuente: Autores, 2019, basados en IDEA (2005) y en talleres de trabajo con equipo técnico del MINVU y Universidad de Chile. 


\section{RESULTADOS}

Se han evaluado los logros y avances en RRD obtenidos en los 3 casos seleccionados, utilizando la Tabla de Evaluación de Logros utilizando la metodología propuesta por el IGR en las tres fases del programa: Fase I - Identificación del Riesgo; Fase II - Reducción de Riesgos y Manejo de Desastres; y Fase III - Evaluación de la estrategia de RRD.

Esto ha permitido conocer en qué etapas de la propuesta y fases se lograron los mayores avances y cuáles de ellas fueron deficientes y requieren de mayores esfuerzos. Se resume a continuación los resultados del análisis de los datos de acuerdo a la ejecución cronológica de las intervenciones.

Evalaución IGR Barrio Rodelillo, Incendio 2013:

Identificación del Riesgo:

Reducción de Riesgos:

Manejo de Desastres:

Evaluación de la estrategia de GRD:

\section{Deficiente}

\section{Deficiente}

Aceptable

Deficiente

El Plan Maestro Rodelillo (ver Figura 4) considera una inversión de M\$7.335.875 de pesos chilenos (US \$10.499.019), llegando a 4.700 viviendas, 19.740 habitantes, en una superficie de 10.000 hectáreas.

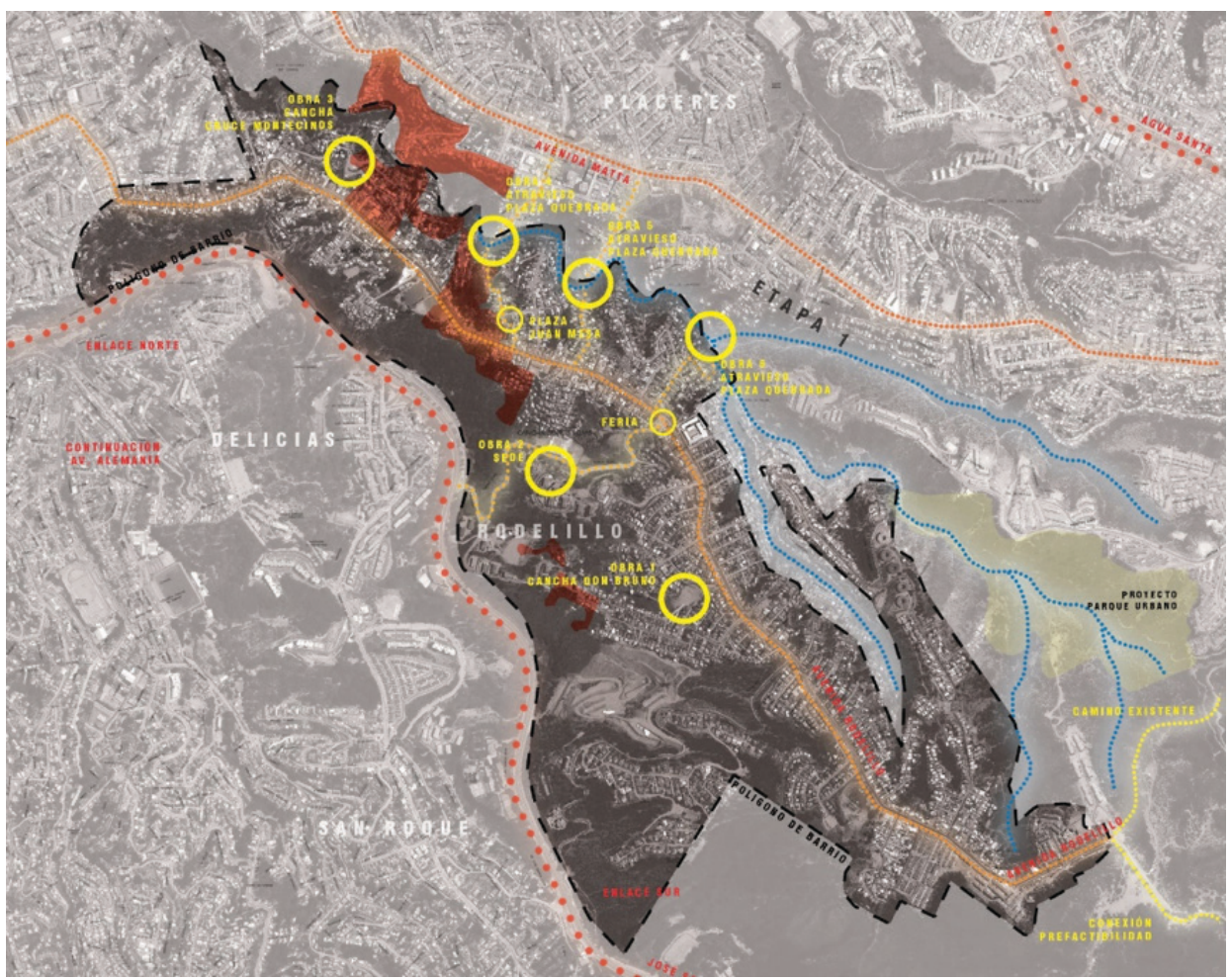

Figura 4. Plan Maestro Rodelillo, Valparaíso

Fuente: Autores, 2019. 


\begin{tabular}{|c|c|c|c|c|}
\hline \multicolumn{3}{|c|}{ Actividad de RRD } & $\begin{array}{l}\text { Marque } \\
\operatorname{con} X\end{array}$ & Nivel de Desempeño \\
\hline \multicolumn{5}{|c|}{ FASEI } \\
\hline \multirow{10}{*}{$\begin{array}{l}\text { Identificación del } \\
\text { Riesgoo } \\
\text { (IR) }\end{array}$} & \multicolumn{2}{|c|}{ 1. Revisión de Instrumentos de Planificación Territorial y estudios de riesgo. } & $x$ & \multirow{10}{*}{$\begin{array}{l}\text { Deficiente: Se realizaron entre } 0 \text { y } 3 \\
\text { actividades de RRD. } \\
\text { Aceptable: Se realizaron entre } 4 \text { y } 6 \\
\text { actividades de RRD. } \\
\text { Óptimo: Se realizaron entre } 7 \text { y } 9 \\
\text { actividades de RRD. }\end{array}$} \\
\hline & \multicolumn{2}{|c|}{$\begin{array}{l}\text { 2. Aplicación de encuesta de caracterización, percepción y satisfacción y } \\
\text { Memoria Histórica de Desastres. }\end{array}$} & & \\
\hline & \multirow{4}{*}{$\begin{array}{l}\text { Recorridos } \\
\text { Barriales }\end{array}$} & 3. Taller de Introducción a la RRD. & & \\
\hline & & 4. Recorrido barrial. & & \\
\hline & & 5. Cartografía Participativa de Riesgo de Desastres. & & \\
\hline & & 6. Mapa Técnico de Riesgo de Desastres. & & \\
\hline & \multicolumn{2}{|c|}{ 7. Conformación COE Barrial. } & & \\
\hline & \multicolumn{2}{|c|}{ 8. Incorporación de capítulo sobre RRD en Diagnóstico Compartido. } & & \\
\hline & \multicolumn{2}{|c|}{ 9. Desarrollo de Perfiles de Proyectos de RRD en el Plan Maestro. } & $\mathbf{x}$ & \\
\hline & \multicolumn{2}{|c|}{ NÚMERO TOTAL DE ACTIVIDADES REALIZADAS } & 2 & \\
\hline \multirow{5}{*}{$\begin{array}{l}\text { Reducción del Riesgo } \\
\text { (RR) }\end{array}$} & \multicolumn{3}{|c|}{ FASE II } & \\
\hline & \multirow{2}{*}{$\begin{array}{l}\text { Plan de Gestión } \\
\quad \text { de Obras }\end{array}$} & $\begin{array}{l}\text { 1. Desarrollo de Obras de Mitigación y Mejoramiento de la } \\
\text { Seguridad en Espacios públicos. }\end{array}$ & $\mathrm{x}$ & \multirow{4}{*}{$\begin{array}{c}\text { Deficiente: Se realizaron entre } 0 \text { y } 1 \\
\text { actividad de RRD. } \\
\text { Aceptable: Se realizaron } 2 \text { actividades de } \\
\text { RRD. } \\
\text { Óptimo: Se realizaron las } 3 \text { actividades de } \\
\text { RRD. }\end{array}$} \\
\hline & & $\begin{array}{l}\text { 2. Implementación de Zonas de Seguridad y Vías de } \\
\text { Evacuación. }\end{array}$ & & \\
\hline & $\begin{array}{l}\text { Plan de Gestión } \\
\text { de Viviendas }\end{array}$ & $\begin{array}{l}\text { 3. Desarrollo de Talleres de Seguridad al interior de la } \\
\text { vivienda. }\end{array}$ & & \\
\hline & \multicolumn{2}{|c|}{ NÚMERO TOTAL DE ACTIVIDADES REALIZADAS } & 1 & \\
\hline \multirow{3}{*}{$\begin{array}{l}\text { Manejo del Desastre } \\
\text { (MD) }\end{array}$} & \multirow{2}{*}{$\begin{array}{l}\text { Plan de Gestión } \\
\text { Social }\end{array}$} & 1. Desarrollo de Talleres por Tipo de Amenaza. & & \multirow{3}{*}{$\begin{array}{c}\text { Deficiente: No se realizaron actividades de } \\
\text { RRD. } \\
\text { Aceptable: Se realizó } 1 \text { actividad de RRD. } \\
\text { Óptimo: Se realizaron } 2 \text { actividades de } \\
\text { RRD. }\end{array}$} \\
\hline & & $\begin{array}{l}\text { 2. Coordinación Multisectorial para la preparación, } \\
\text { respuesta y recuperación. }\end{array}$ & $\mathrm{x}$ & \\
\hline & \multicolumn{2}{|r|}{ NÚMERO TOTAL DE ACTIVIDADES REALIZADAS } & 1 & \\
\hline \multicolumn{5}{|c|}{ FASE III } \\
\hline \multirow{5}{*}{$\begin{array}{c}\text { Evaluación de la } \\
\text { Estrategia } \\
\text { (EE) }\end{array}$} & \multicolumn{2}{|c|}{ 1. Aplicación de Encuesta de Verificación de Resultados. } & & \multirow{5}{*}{$\begin{array}{c}\text { Deficiente: Se realizaron entre } 0 \text { y } 1 \\
\text { actividades de RRD. } \\
\text { Aceptable: Se realizaron entre } 2 \text { y } 3 \\
\text { actividades de RRD. } \\
\text { Óptimo: Se realizaron las } 4 \text { actividades de } \\
\text { RRD. }\end{array}$} \\
\hline & \multicolumn{2}{|c|}{ 2. Incorporación de Capítulo de Memoria Histórica en "Historia de Barrio". } & & \\
\hline & \multicolumn{2}{|c|}{ 3. Incorporación de Capítulo de RRD en Informe Final. } & & \\
\hline & \multicolumn{2}{|c|}{$\begin{array}{l}\text { 4. Existencia de un Compromiso Municipal de continuidad de la RRD en Agenda } \\
\text { Futura. }\end{array}$} & & \\
\hline & \multicolumn{2}{|r|}{ NÚMERO TOTAL DE ACTIVIDADES REALIZADAS } & 0 & \\
\hline
\end{tabular}

Tabla 4. Tabla de Evaluación de Logros IGR para Barrio Rodelillo, Incendio 2013

Fuente: Autores, 2019.

Evaluación IGR Barrio Cerro la Cruz, Incendio 2014:

Identificación del Riesgo:

Reducción de Riesgos:

Manejo de Desastres:

Evaluación de la estrategia de GRD:

\section{Aceptable}

Óptimo

Óptimo

Aceptable

El Plan Maestro Cerro La Cruz (ver Figura 5) consideró una inversión de $M \$ 1.921 .094$ de pesos chilenos (US \$2.749.447), 1.080 vivienda, 4.320 habitantes, en una superficie de 39 hectáreas

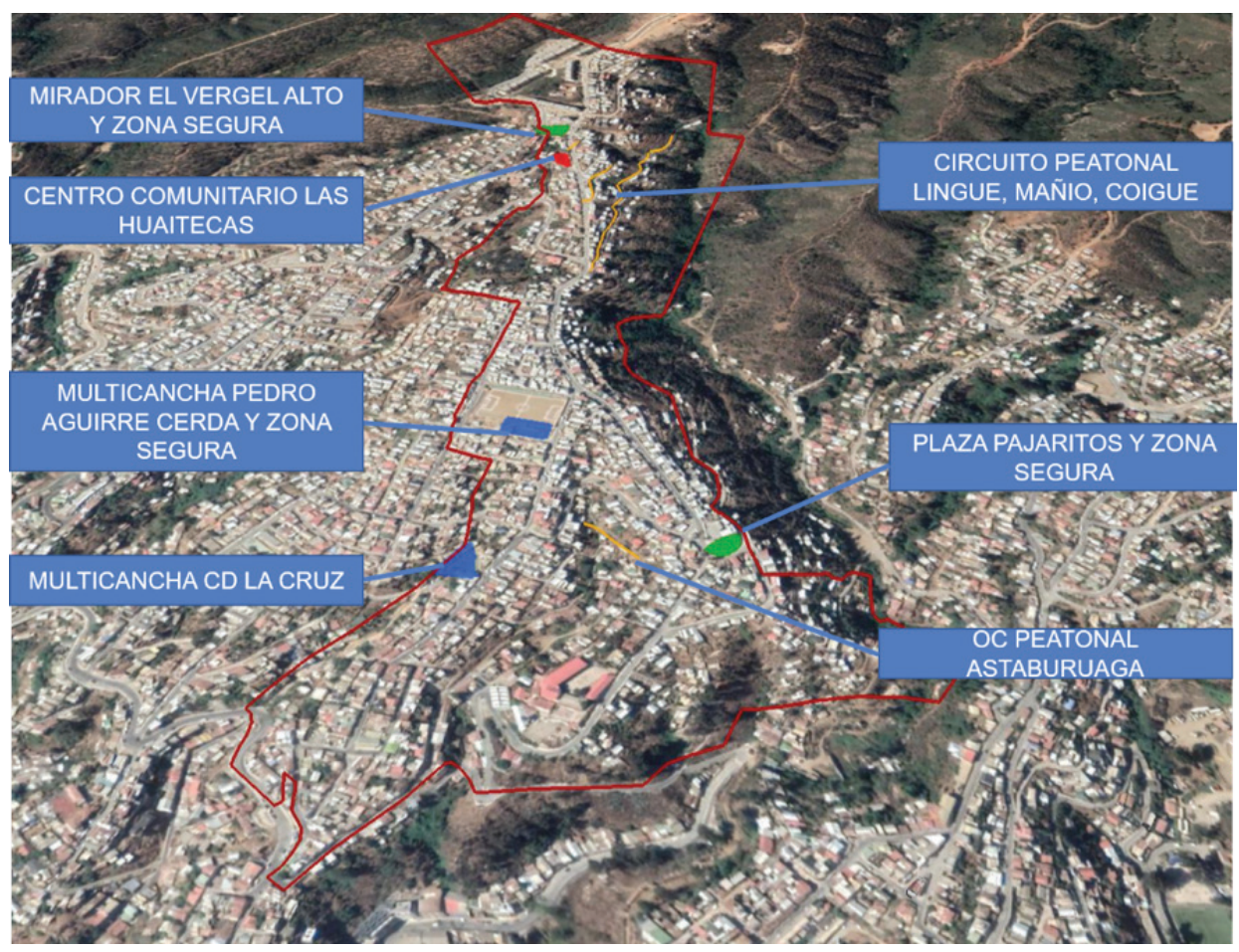

Figura 5. Plan Maestro Cerro La Cruz, Valparaíso

Fuente: Autores, 2019. 


\begin{tabular}{|c|c|c|c|c|}
\hline \multicolumn{3}{|c|}{ Actividad de RRD } & $\begin{array}{l}\text { Marque con } \\
\mathrm{X}\end{array}$ & Nivel de Desempeño \\
\hline \multicolumn{5}{|c|}{ FASEI } \\
\hline \multirow{10}{*}{$\begin{array}{l}\text { Identificación } \\
\text { del Riesgo } \\
\text { (IR) }\end{array}$} & \multicolumn{2}{|c|}{ 1. Revisión de Instrumentos de Planificación Territorial y estudios de riesgo. } & $\mathrm{x}$ & \multirow{10}{*}{$\begin{array}{l}\text { Deficiente: Se realizaron entre } 0 \text { y } 3 \\
\text { actividades de RRD. } \\
\text { Aceptable: Se realizaron entre } 4 \text { y } 6 \\
\text { actividades de RRD. } \\
\text { Óptimo: Se realizaron entre } 7 \text { y } 9 \\
\text { actividades de RRD. }\end{array}$} \\
\hline & \multicolumn{2}{|c|}{$\begin{array}{l}\text { 2. Aplicación de encuesta de caracterización, percepción y satisfacción y Memoria } \\
\text { Histórica de Desastres. }\end{array}$} & $\mathrm{n} / \mathrm{a}$ & \\
\hline & \multirow{4}{*}{ Recorridos Barriales } & 3. Taller de Introducción a la RRD. & & \\
\hline & & 4. Recorrido barrial. & $\mathbf{x}$ & \\
\hline & & 5. Cartografía Participativa de Riesgo de Desastres. & & \\
\hline & & 6. Mapa Técnico de Riesgo de Desastres. & & \\
\hline & \multicolumn{2}{|c|}{ 7. Conformación COE Barrial. } & & \\
\hline & \multicolumn{2}{|c|}{ 8. Incorporación de capítulo sobre RRD en Diagnóstico Compartido. } & $\mathrm{x}$ & \\
\hline & \multicolumn{2}{|c|}{ 9. Desarrollo de Perfiles de Proyectos de RRD en el Plan Maestro. } & $x$ & \\
\hline & \multicolumn{2}{|c|}{ NÚMERO TOTAL DE ACTIVIDADES REALIZADAS } & 4 & \\
\hline \multicolumn{5}{|c|}{ FASE II } \\
\hline \multirow{4}{*}{$\begin{array}{l}\text { Reducción del } \\
\text { Riesgo (RR) }\end{array}$} & \multirow{2}{*}{$\begin{array}{l}\text { Plan de Gestión de } \\
\text { Obras }\end{array}$} & $\begin{array}{l}\text { 1. Desarrollo de Obras de Mitigación y Mejoramiento de la } \\
\text { Seguridad en Espacios públicos. }\end{array}$ & $\mathbf{x}$ & \multirow{4}{*}{$\begin{array}{c}\text { Deficiente: Se realizaron entre } 0 \text { y } 1 \\
\text { actividad de RRD. } \\
\text { Aceptable: Se realizaron } 2 \text { actividades de } \\
\text { RRD. } \\
\text { Óptimo: Se realizaron las } 3 \text { actividades de } \\
\text { RRD. }\end{array}$} \\
\hline & & $\begin{array}{l}\text { 2. Implementación de Zonas de Seguridad y Vías de } \\
\text { Evacuación. }\end{array}$ & $\mathbf{x}$ & \\
\hline & $\begin{array}{l}\text { Plan de Gestión de } \\
\text { Viviendas }\end{array}$ & $\begin{array}{l}\text { 3. Desarrollo de Talleres de Seguridad al interior de la } \\
\text { vivienda. }\end{array}$ & $\mathrm{x}$ & \\
\hline & \multicolumn{2}{|c|}{ NÚMERO TOTAL DE ACTIVIDADES REALIZADAS } & 3 & \\
\hline \multirow{3}{*}{$\begin{array}{l}\text { Manejo del } \\
\text { Desastre } \\
\text { (MD) }\end{array}$} & \multirow{2}{*}{$\begin{array}{l}\text { Plan de Gestión } \\
\text { Social }\end{array}$} & 1. Desarrollo de Talleres por Tipo de Amenaza. & $x$ & \multirow{3}{*}{$\begin{array}{c}\text { Deficiente: No se realizaron actividades de } \\
\text { RRD. } \\
\text { Aceptable: Se realizó } 1 \text { actividad de RRD. } \\
\text { Óptimo: Se realizaron } 2 \text { actividades de } \\
\text { RRD. }\end{array}$} \\
\hline & & $\begin{array}{l}\text { 2. Coordinación Multisectorial para la preparación, } \\
\text { respuesta y recuperación. }\end{array}$ & $\mathbf{x}$ & \\
\hline & \multicolumn{2}{|c|}{ NÚMERO TOTAL DE ACTIVIDADES REALIZADAS } & 2 & \\
\hline & & FASE III & & \\
\hline \multirow{5}{*}{$\begin{array}{c}\text { Evaluación de } \\
\text { la Estrategia } \\
\text { (EE) }\end{array}$} & \multicolumn{2}{|c|}{ 1. Aplicación de Encuesta de Verificación de Resultados. } & $x$ & \multirow{5}{*}{$\begin{array}{c}\text { Deficiente: Se realizaron entre } 0 \text { y } 1 \\
\text { actividades de RRD. } \\
\text { Aceptable: Se realizaron entre } 2 \text { y } 3 \\
\text { actividades de RRD. } \\
\text { Óptimo: Se realizaron las } 4 \text { actividades de } \\
\text { RRD. }\end{array}$} \\
\hline & \multicolumn{2}{|c|}{ 2. Incorporación de Capítulo de Memoria Histórica en "Historia de Barrio". } & $\mathbf{x}$ & \\
\hline & \multicolumn{2}{|c|}{ 3. Incorporación de Capítulo de RRD en Informe Final. } & $\mathbf{x}$ & \\
\hline & \multicolumn{2}{|c|}{$\begin{array}{l}\text { 4. Existencia de un Compromiso Municipal de continuidad de la RRD en Agenda } \\
\text { Futura. }\end{array}$} & 0 & \\
\hline & \multicolumn{2}{|c|}{ NÚMERO TOTAL DE ACTIVIDADES REALIZADAS } & 3 & \\
\hline
\end{tabular}

Tabla 5. Tabla de Evaluación de Logros IGR Barrio para Barrio Cerro La Cruz, Incendio 2014 Fuente: Autores, 2019.

Evaluación IGR Barrio Puertas Negras, Incendio 2017:

$\begin{array}{ll}\text { Identificación del Riesgo: } & \text { Óptimo } \\ \text { Reducción de Riesgos: } & \text { Óptimo } \\ \text { Manejo de Desastres: } & \text { Óptimo } \\ \text { Evaluación de la estrategia de GRD: } & \text { Óptimo }\end{array}$

El Plan Maestro del Barrio Puertas Negras (ver Figura 6) consideró una inversión de M\$1.053.953 de pesos chilenos (US \$1.508.405), 645 viviendas, 2004 habitantes, en una superficie 29 hectáreas.

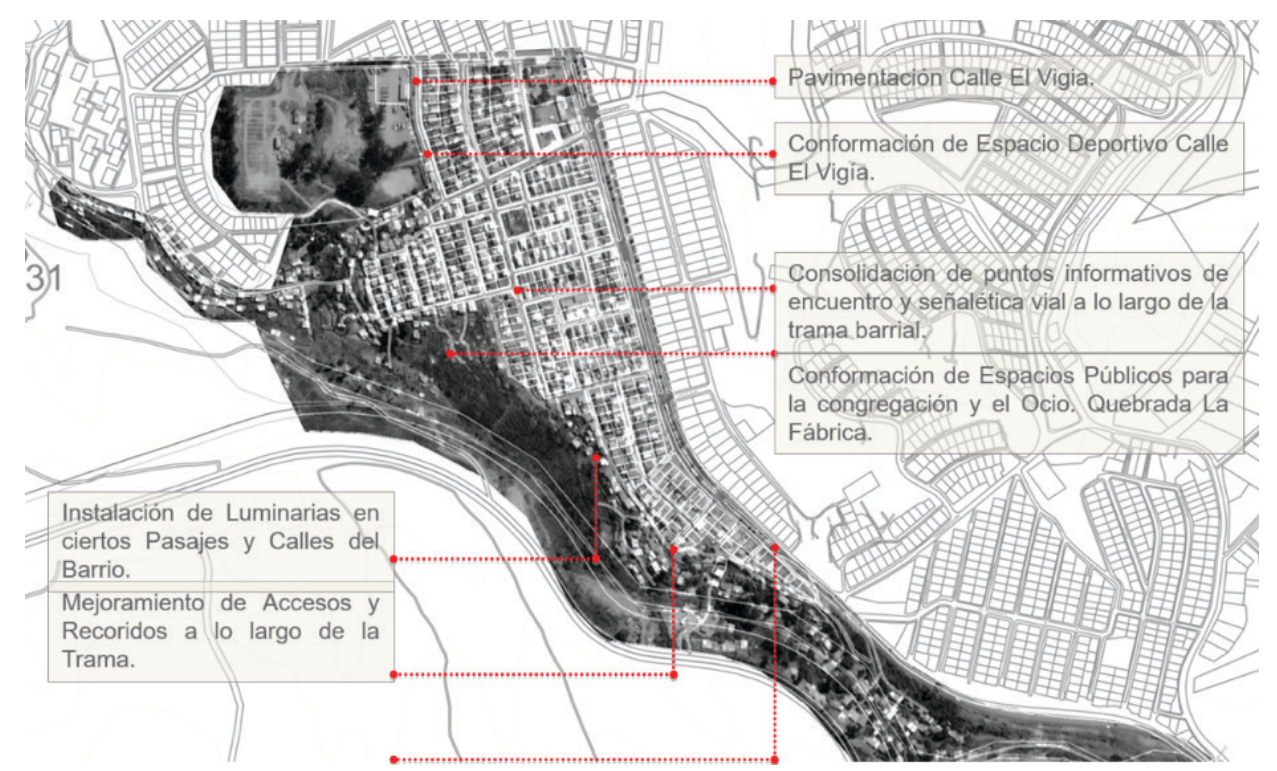

Figura 6. Plan Maestro del Barrio Puertas Negras, Valparaíso

Fuente: Autores, 2019. 


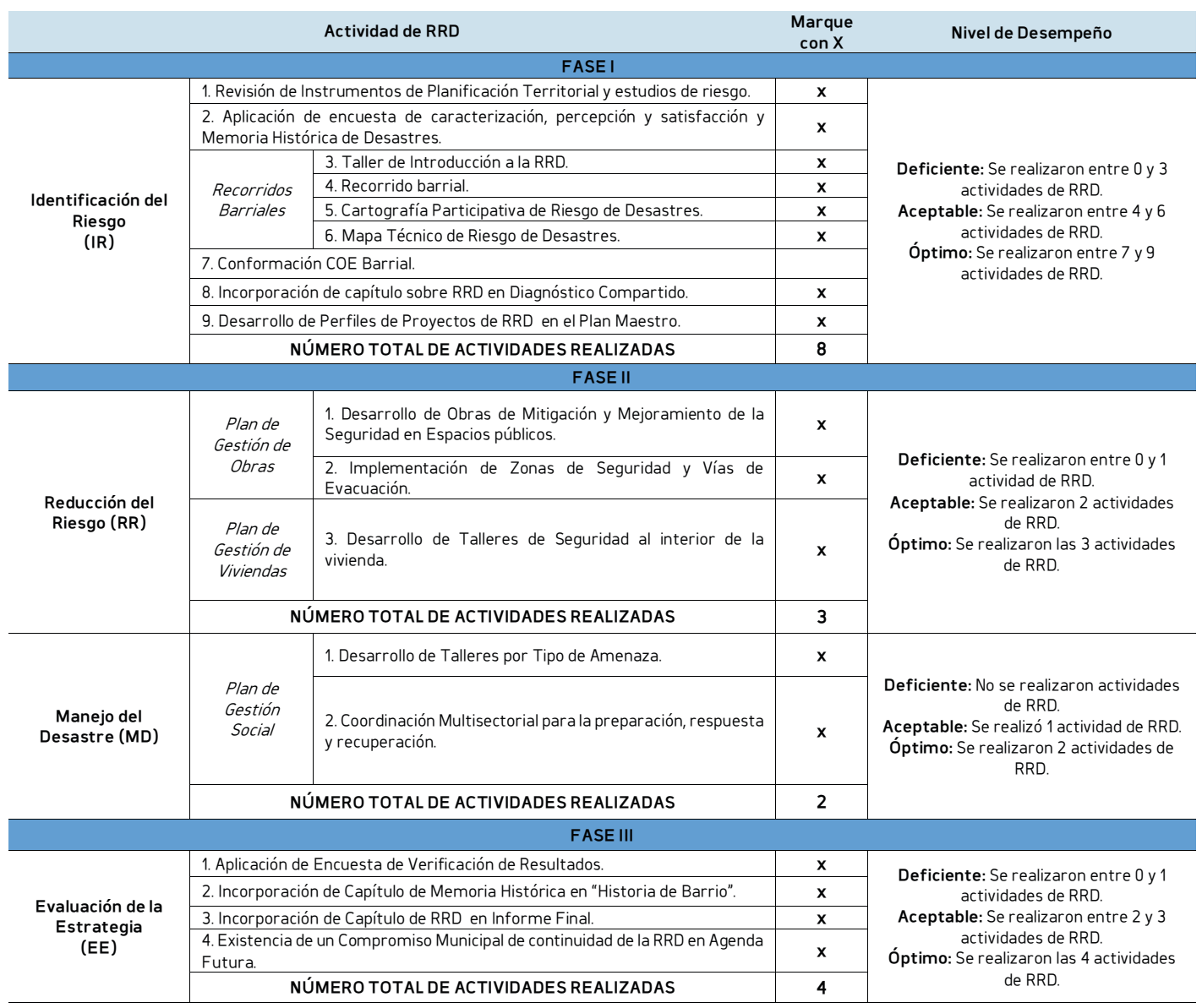

Tabla 6. Tabla de Evaluación de Logros Barrio IGR para Barrio Puertas Negras, Incendio 2017 Fuente: Autores, 2019

Tras la aplicación del IGR en los 3 barrios de Valparaíso se puede observar que en la primera intervención ocurrida tras el incendio 2013 en el Barrio Rodelillo, los resultados arrojaron que tres de cuatro campos eran deficientes. Se destaca en esta primera experiencia de RRD, la creación de las instalaciones de red seca en pasajes y senderos peatonales públicos, elementos que son exigibles para la construcción de edificios. Debido a lo complicado que resultaba para bomberos el combate de incendios en lugares de difícil acceso, se toma la decisión de implementar estas redes secas, las que consisten en cañerías sin agua y de uso exclusivo de bomberos, permitiendo unir los carro-bomba mediante una manguera a la entrada de la red, enviando el agua por medio de presión hacia la zona donde se produce el incendio.

En el Barrio Cerro La Cruz, afectado por un incendio el 2014, los resultados de la aplicación del IGR arrojaron que dos de cuatro campos eran Aceptables y dos Óptimos. La ejecución del Programa Quiero mi Barrio en este barrio comenzó en agosto de 2014, cuatro meses después de ocurrida la emergencia. Al comenzar la intervención, gran parte de sus habitantes se encontraban residiendo fuera del territorio producto de la destrucción de sus viviendas, mientras que la respuesta del gobierno permitió generar subsidios al pago de arriendo o acogida de los afectados mientras se reconstruían las viviendas a través de alguno de los programas de reconstrucción de viviendas. En este barrio, se tomó la determinación de no aplicar la Encuesta de Entrada (Fase I) de Caracterización, Percepción y Satisfacción del Programa Quiero mi Barrio debido al desgaste de la comunidad producto del impacto psicológico y social que significo vivenciar una catástrofe de tal magnitud. Sin embargo, a través de los datos de otra encuesta, la Encuesta Familiar Única de Emergencia (EFU), se pudo estimar cuántas familias y personas fueron afectadas por el incendio. Ésta permitió además evaluar las demandas sociales, habitacionales y las necesidades de cada grupo familiar, permitiendo orientar la entrega de soluciones habitacionales a las familias. Sin embargo, una vez más avanzada la recuperación, se aplicó la Encuesta de Salida (Fase III) de Caracterización, Percepción y Satisfacción del Programa.

Durante el desarrollo de los recorridos barriales y el desarrollo de los perfiles de proyecto, se realizaron en forma complementaria pasantías que permitieron a los residentes del barrio La Cruz 
conocer el alcance del Programa Quiero mi Barrio en otros barrios que habían sufrido desastres con anterioridad y que ya habían superado la etapa de emergencia. Para ello, se realizaron visitas a la ciudad de Constitución, la cual fue afectada por un tsunami producto del terremoto del 27 de febrero de 2010 en la zona central de Chile. En el mismo barrio, una vez priorizadas por la comunidad las obras del contrato de barrio que se ejecutarían durante la Fase II, se identificaron iniciativas con un enfoque en RRD tal como la construcción de sedes comunitaria -que permiten albergar a la comunidad ante emergencias, creación de zonas de seguridad en plazas, áreas verdes y recintos deportivos y la instalación de redes secas en pasajes y senderos peatonales con un costo de implementación de $\$ 1.300 .000$ (US \$1.870) por cada 45 metros lineales. Además, se identificaron iniciativas dentro del Plan de Gestión Social, que buscaban entregar conocimientos, capacidades y herramientas a la comunidad y sus dirigentes, tales como capacitación en primeros auxilios, identificación y reconocimiento de los distintos tipos de riesgos y sus amenazas, formación de brigadas de riesgos, y equipamiento radial.

A través de la creación de Brigada de Riesgos se estableció un plan de acción que identificó roles y funciones para cada una de sus integrantes de tales brigadas: Encargados de Barrio; Encargados de Comunicaciones; y Encargado de Sedes comunitarias. Se distribuyó una radio con frecuencia UFH/VHF en cada sector para coordinar el funcionamiento de las brigadas durante emergencias con la municipalidad de Valparaíso. Estas brigadas y el uso de radios son fundamental para asegurar la comunicación entre los servicios de emergencia tanto de la municipalidad como de otros organismos del Estado- y las comunidades, especialmente cuando los canales de comunicación tradiciones (telefonía fija y móvil) fallan.

Por otro lado, el desarrollo del Plan de Reducción de Riesgos de Desastres se evaluó positivamente ya que el taller en el cual se desarrolló planteó un espacio reflexivo y participativo, en donde se analizaron aspectos teóricos y prácticos desarrollados durante el periodo de ejecución. Las instancias reflexivas y participativas son fundamentales en la configuración de una cultura preventiva en torno a desastres y catástrofes. Durante el desarrollo del taller, la brigada logró empoderarse y apropiarse del espacio público y hacerlo parte de una cultura preventiva y ambiental. Pese a lo anterior, continúan presentándose situaciones que requieren abordar la RRD de manera más intensiva. Por un lado, los participantes consideran que las acciones que realizan los vecinos para prevenir los riesgos en sus barrios son efectivas: la limpieza del entorno, la buena comunicación, y organización entre vecinos, en conjunto con un porcentaje de $21,3 \%$. Por otro lado, las dificultades que enfrentan en sus barrios para implementar la gestión de riesgos son importantes: se presenta en primer lugar el desinterés y falta de organización vecinal $(32 \%)$, seguido por la falta de conocimiento sobre estas temáticas (15\%). No obstante, se destacó la acción espontanea de la comunidad ante la eventual ocurrencia de emergencia, observada a través de la Encuesta de Caracterización y Percepción realizada durante la Fase III -un 63\% declara que la comunidad se organiza en caso de catástrofe.

El barrio Puertas Negras de Valparaíso inició su intervención tras un grave incendio el 2017, Al iniciar la intervención se contaba con el IGR, por lo que sus contenidos fueron considerados en la planificación de la intervención desde su diagnóstico, diseño y ejecución del Plan Maestro y su etapa de evaluación. El IGR arrojó que las actividades desarrolladas responden a un nivel Óptimo de logros. Actualmente el barrio está en plena ejecución de su Fase II. Puertas Negras es un sector periférico de la comuna de Valparaíso, ubicándose en la parte alta de playa ancha. Este barrio se conforma en el año 1965 con las llegadas de familias provenientes de distintos cerros de Valparaíso, los cuales fueron desplazados por el terremoto del mismo año. Aunque no fue considerado en profundidad, el hecho de que la conformación de este barrio este estrechamente vinculada a una catástrofe es un elemento relevante de la historia y desarrollo del barrio. Por otro lado, la selección de Puertas Negras respondió a la urgencia de intervenir en un sector afectado por un desastre reciente (incendio en 2017). El Programa Quiero mi Barrio ingresó a este territorio como parte de una estrategia de reconstrucción en conjunto con Reconstrucción SERVIU (Servicios de Vivienda y Urbanización, del MINVU), Reconstrucción Municipal, y otros actores institucionales. Hasta el día de hoy, el barrio presenta problemáticas habitacionales y urbanas que trascienden a la intervención que se pueda desarrollar desde el programa, por ende, la etapa de diagnóstico del barrio fue consensuada y abordada desde la comunidad, priorizándose las obras que estuvieran enfocadas a la prevención de riesgos, y en el ámbito social a la generación de capacidades en la comunidad para enfrentar situaciones de emergencia. Del diagnóstico se desprende que el barrio presenta un importante déficit urbano reflejado en la falta de áreas verdes, equipamientos y vías de acceso, así también situaciones sociales que afectan la convivencia y la vida en comunidad. Este deterioro, en 
vez de retroceder, se perpetúa a partir del abandono sistemático desde la política pública, gobierno local y la falta de una planificación territorial coherente con las necesidades de esta comunidad en particular, el cual se transforma en una oportunidad al momento de plantear las intervenciones del Plan Maestro.

\section{CONCLUSIONES}

A partir de la información presentada y en las reflexiones surgidas desde la práctica de los autores en el diseño, desarrollo, y ejecución del Programa Quiero mi Barrio al aplicar el IGR en los tres casos expuestos entre el año 2013 y 2017, se presentan a continuación cuatro conclusiones.

1. Al aplicar la herramienta de IGR en tres barrios intervenidos por el Programa Quiero mi Barrio, se comprobó que sí se puede reducir el riesgo de desastres con medidas concretas que no necesariamente impactan en el presupuesto del programa al elaborar planes de reducción de riesgos con obras de mitigación, definición de vías de evacuación y zonas seguras, junto con un plan de emergencia adecuado que coordine a los vecinos con el municipio.

2. La inversión pública puede ser encausada hacia transformaciones barriales resilientes al incorporar medida de RRD en sus procesos de diagnóstico, planificación e implementación de un plan maestro.

3. La gestión del gobierno local es muy relevante al momento de implementar una estrategia de gestión de riesgos en los territorios. Los gobiernos locales son los organismos que debe liderar estos procesos frente a la comunidad y los otros actores institucionales y privados que son parte del territorio, promoviendo un proceso participativo, reflexivo e interdisciplinario, que, tras la identificación de un diagnóstico en común, desarrolle una estrategia articulada que apunte a revertir las problemáticas y potenciar las fortalezas del barrio, apalancando recursos al plan desde la multisectorialidad.

4. Reforzar el capital social como estrategia socioeducativa en los barrios con altos índices de vulnerabilidad permite generar capacidades reactivas frente a eventos o catástrofes. Además, se favorece el fomento de acciones preventivas planificadas con todos los actores del territorio.

\section{REFERENCIAS}

Blaikie, P., Cannon, T., David, I. \& Wisner, B. (1996). Vulnerabilidad: el entorno social, político y económico de los desastres. Bogotá: Tercer Mundo Editores.

Castro, C.P., Ortíz, J., Delgado, J., Jiménez, V., Quiroga, S., Sosa, E. \& Sarmiento, J.P. (2008). Aproximación Metodológica a una Articulación entre Gestión del Riesgo, Gestión Ambiental y Ordenamiento Territorial. Geograficando, 4(4), 159-177.

Instituto de Estudios Ambientales IDEA. (2005). Sistema de Indicadores para la Gestión del Riesgo de Desastres: Informe Técnico Principal. Manizales: Programa de Indicadores para la Gestión de Riesgos BID-IDEA, Instituto de Estudios Ambientales \& Universidad Nacional de Colombia, Sede Manizales.

Ministerio de Vivienda y Urbanismo MINVU. (2008). Manual de Procedimientos Programa de Recuperación de Barrios. Santiago de Chile: Gobierno de Chile.

Oficina Nacional de Emergencias ONEMI. (2014). Política Nacional para la Gestión del Riesgo de Desastres. Santiago de Chile: ONEMI.

Oficina Nacional de Emergencias ONEMI. (2016). Plan Estratégico Nacional para la Gestión del Riesgo de Desastres. Plataforma Nacional para la Reducción del Riesgo de Desastres. Santiago de Chile: ONEMI.

United Nations International Strategy for Disaster Reduction UNISDR. (2015). Marco de Sendai para la Reducción del Riesgo de Desastres 2015-2030. Sendai: Naciones Unidas.

Yamin, E., Ghesquiere, F., Cardona, O. \& Ordaz, M. (2013). Modelación probabilista para la gestión del riesgo de desastre: el caso de Bogotá, Colombia. Bogotá: Banco Mundial \& Universidad de los Andes. 